\title{
Tracing Dialect Death: The Texas German Dialect Project
}

\author{
HANS C. BOAS
}

University of Texas at Austin

\section{Introduction}

This paper reports on current efforts of the Texas German Dialect Project to record, archive, and analyze the remnants of the rapidly eroding Texas German dialect spoken in central Texas. 'The paper is structured as follows. Section one gives a brief history of German settlements in central Texas. Section two presents in detail the on-going activities of the Texas German Dialect Project. They include conducting fieldwork in three representative speech communities and the creation of an on-line digital archive of Texas German. Section three discusses the change of a selected number of lexical, morphological, syntactic, and phonological features of Texas German that took place over the last four decades. More specifically, it compares data from thirty to forty years ago with data recorded during current fieldwork in fall of 2001 and spring of 2002. Finally, section four gives an overview of research questions that the Texas German Dialect Project will be tackling as it will be collecting and analyzing more data over the coming years.

\section{Brief History of German Settlements in Central Texas}

The Texas German speakers who live across central Texas are in large part the descendants of settlers that started emigrating from Germany beginning around 1830 (Biesele 1928, Salmons 1983). ${ }^{2}$ The first large group of about 5000 settlers came to Texas in 1845/46 as part of an organized effort by the "Society for the Protection of German Immigrants to Texas" that was organized by a group of German noblemen with the goal of systematically settling Germans in Texas.

The different dialects of the settlers' native homes in geographically diverse places such as Hesse, Hesse-Nassau, Rhenish Prussia, Westphalia, and Hannover

\footnotetext{
${ }^{1}$ The Texas German Dialect Project (TGDP) gratefully acknowledges the financial support of the Dean of Liberal Arts, the Vice President for Research, and the Center for Instructional Technologies, all of the University of Texas at Austin.

${ }^{2}$ According to Gilbert (1965), the majority of Texas German speakers "are located in the eastern part of the state between Austin and Houston and on the eastern part of the Edwards Plateau west of Austin and San Antonio" (1965: 102).
} 
formed the basis from which the dialects of New Braunfels, Fredericksburg, and other Texas German communities evolved (cf. Eikel (1949: 278), Gilbert (1965: 102)). Because of their isolation at the western frontier, these towns became important regional cultural centers which enabled German immigrants and their descendants to maintain their culture and language for an exceptionally long time (Salmons 1983, Guion 1996, Boas, in press).

However, due to the wave of anti-German sentiment caused by the two World Wars, the prestige of German in the United States suffered severe blows and the generally stable linguistic situation of Texas German began to collapse. ${ }^{3}$ The social, demographic, and economic changes that took place in central Texas following World War II led to schooling exclusively in English in a culture that had an extensive system of German schools. ${ }^{4}$ Moreover, English gained in prestige among younger speakers because of the practical and economic advantages associated with being primarily English-speaking (Salmons 1983, Guion 1996, Boas, in press).

The decline in prestige associated with speaking Texas German led to the dialect not being transmitted to children to any significant extent. Whereas for generations Texas German was acquired in early childhood at home, this form of transmission disappeared in the years following World War II. The continuation of these trends over the last five decades has resulted in a sharp decrease in the number of fluent Texas German speakers, thereby causing a rapid language shift to English in the Texas German community. At present, English has become the primary language for most Texas Germans in both private and public domains, whereas the reverse would still have been true as late as the 1940s (Salmons 1983, Boas, in press). As Guion (1996) points out:

The last two environments outside the home that afforded a possibility of speaking German, namely business transactions and church, have been lost. Presently, the only surviving register is an informal, familial one. It is important to note here that German is strictly used for oral purposes. The only written German found in German-speaking homes is an occasional family Bible. English is the sole language written by the people interviewed (p.447).

The remaining number of fluent Texas German speakers in central Texas, most of whom are age 60 or older, is estimated to be between 6-7000 (compared to ca. 70,000 in the early 1960s, according to Gilbert (1965: 102)) (see Boas (in

\footnotetext{
${ }^{3}$ See Eikel (1949) and Salmons (1983) for a more detailed discussion.

${ }^{4}$ One of the most influential measures affecting the prestige of Texas German has probably been the passing of English-only laws by the Texas Legislature at the beginning of World War I. This legislation required English to be the language of instruction in public schools as well as for all official transactions (Guion 1996: 444). Although in 1938 the English-only policies were loosened to allow for instruction in German above the second grade, the prestige of Texas German had already suffered severe blows such that "the young people [who] had been schooled in English (...) could much more easily identify with the more prestigious English and disappear into the melting pot" (Salmons 1983: 188).
} 
press)). The rapidly shrinking number of fluent Texas German speakers as well as the limited domains and registers of use puts this dialect on the list of about 1200 moribund dialects world-wide that are expected to go extinct within the next 2025 years (see Crystal (2000)).

\section{The Texas German Dialect Project (TGDP)}

As a response to this situation, the Texas German Dialect Project (henceforth TGDP) was founded in September 2001 with the goal of recording, archiving, and analyzing the remnants of the rapidly eroding Texas German dialect. The following sections give an overview of the work flow of the TGDP. The first step in setting up the TGDP consisted of collecting and reviewing all publicly available previous work on Texas German. The purpose of this preliminary phase was to identify the relevant linguistic features of Texas German recorded by earlier studies ${ }^{5}$ in order to set up procedures that would allow for eliciting as much relevant data from informants as possible.

\subsection{Design of Questionnaire}

The second step was to derive a strategy that would allow for a broad-scale collection of natural data representing the largest possible number of linguistic features of Texas German. One option considered for collecting data consisted of using structured word lists and sentences to be translated by informants from English to German. In addition, structured word lists and sentences in German were considered for serving as a basis for eliciting information on how informants pronounced words and sentences differently.

However, due to their narrow scope (each covered only a limited number of words and sentences), both methods would have only yielded a limited amount of linguistic information. Another disadvantage of this approach is that the data collected would not have been elicited in a natural setting. That is, the informants' daily use of Texas German would not have been replicated or understood by simply having them read or translate structured word and sentence lists.

In order to overcome these problems, an eight page long questionnaire was drafted to serve as a basis for sociolinguistic interviews that are more thorough. The first section of the questionnaire contains questions about informants' personal history (date and place of birth, place of origin of informants' ancestors, etc.). The second section of the questionnaire consists of about 140 questions in German about topics including childhood activities, the community, religion, education, living conditions, tourism, government, language, and current activities. The goal of these questions is to produce casual, relaxed conversation in which informants are given the chance to talk naturally. The final section of the

\footnotetext{
${ }^{5}$ For an overview, see the works cited in the bibliography at the end of this paper.
} 
questionnaire contains twenty English sentences that informants are asked to translate into German. ${ }^{6}$

Thus, conducting sociolinguistic interviews with open-ended questions enables data to be gathered on informants' natural speech, as opposed to the artificial/simulated speech imposed by the structured word and sentence lists of previous studies (e.g., Eikel (1967), Gilbert (1972)). Furthermore, by allowing informants to speak freely it becomes possible to discover new linguistic features of Texas German that may have previously gone unnoticed because elicitation methods for them were not included in the research methodology of previous studies.

\subsection{The interview process}

Since the majority of previous studies are concerned with the Texas German varieties spoken in and around Fredericksburg (Gilbert 1963, 1965, 1972, Salmons 1983, Guion 1996) and New Braunfels (Eikel 1949, 1954, 1965, 1967), both towns were natural choices in which to begin fieldwork. Informants were found through a social network tracing process beginning with students at the University of Texas at Austin. Through students enrolled in my classes during the academic year 2001/2002 I was able to make contact with their family members or friends who were at least third generation Texas German speakers residing in Fredericksburg and New Braunfels. Furthermore, colleagues in my department helped me to establish contact with informants in two other locations, namely Round Rock and Freyburg.

Each interview totaled between forty-five and sixty minutes in length. Interviews were conducted in different locations and situations including in informants' homes and on their farms, in hospitals and nursing homes, or while participating in transactions with local business merchants.

Currently, the main task of the TGDP lies in recording as many hours of interviews as possible in order to create as large a data pool of Texas German as possible. This documentation is becoming increasingly pressing because more and more speakers of Texas German are passing away, thereby taking their dialect with them. So far, the youngest informant was 68 years old, and the oldest was 92 years old.

\subsection{The Texas German Dialect Archive (TGDA)}

Interviews are recorded on Mini Disc and/or digital Mini Video, subsequently transferred to the TGDP's main computer, and finally converted into a variety of digital formats for further dissemination. The informants' identity is kept anonymous by assigning each interview a specific number and by deleting the

\footnotetext{
${ }^{6}$ These English sentences are the same sentences used by Susan Guion and John Kaufmann during their fieldwork in Fredericksburg in 1992 and which subsequently served as the basis for Guion (1996). I am grateful to Susan Guion for making a copy of their questionnaire available to me.
} 
first section of the interview in which informants volunteer their personal information.

In order to preserve the recordings for further generations, each interview is burnt onto a number of CDs to be stored in different locations. Furthermore, each interview (or sections thereof) is transcribed and translated. Finally, interviews are stored in the Texas German Dialect Archive (TGDA), a password-protected online archive aimed to make information on Texas German available to a broader audience (see Boas (in press)) ${ }^{7}$

The graphical user interface designed to access the web-based TGDA consists of a digitized map of central Texas listing the different fieldwork sites where members of the TGDP are conducting fieldwork. By clicking on a specific location, e.g., Fredericksburg, users see a pop-up window containing a list of file names giving the length of each available file for that location. Each file name is linked to edited audio/video and text files that contain portions of recordings of linguistic interviews. By clicking on a file name, a Quicktime window opens and plays the file with the combined audio, video, and text data. ${ }^{8}$ Users are able to play the entire file or only parts of it in order to conduct a linguistic analysis of the dialectal features of different speakers of Texas German. While the file is playing, the pop-up text window contains a transcript of the interview and a translation. This feature enables users to understand the recordings more easily, thereby facilitating linguistic analysis of dialectal features. By combining audio, video, and text data and delivering them over the web, users of the TGDA feel as if they are sitting directly across from the Texas German informants as they talk. ${ }^{9}$

As members of the TGDP continue conducting fieldwork, more interviews will be added to the TGDA. Once the TGDA contains a large enough number of recordings of various speakers from different locations across central Texas, it will be possible to start analyzing individual linguistic features of Texas German in more detail. This investigation will not only shed light on the current state of Texas German. It will also yield valuable insights regarding how the dialect has changed since the last in-depth descriptions and analyses of Texas German were conducted some four decades ago.

The following section gives an overview of a number of selected linguistic features extracted from the interviews conducted in spring 2002. Note that the choice of examples is in no way the result of a systematic sampling method-but

\footnotetext{
${ }^{7}$ The web-based TGDA is part of the TGDP web site which also contains information about Texas German heritage and culture, references about Texas German and other German dialects spoken in the United States, and links to other sites concerned with the preservation of endangered languages and their dialects.

${ }^{8}$ The majority of interviews are audio only since informants typically are uncomfortable with them being video taped.

${ }^{9}$ The TGDA is expected to go on-line at the end of August 2002. For a more detailed description, see Boas (in press). Eventually, the content of the recordings as well as their transcriptions and translations are to be aligned. This will allow users to listen to (and view) each interview with subtitles without having to follow the transcription and translation texts in separate windows.
} 
only a collection of representative examples randomly taken from the first twenty hours of recordings. ${ }^{10}$

\section{Texas German in 2002}

\subsection{The lexicon}

As has been pointed out before, Texas German has systematically borrowed English words because German "lacked many names to describe the new environment" (Gilbert 1965: 110). Among the borrowings are words "for new plants, animals, and concepts encountered (e.g., 'armadillo', 'live oak', and 'ranch')" (Guion 1996: 449) or "names of entirely new cultural innovations or technical improvements" such as hay-bailer, sonic boom, and jello (Gilbert 1965: 111).

The fieldwork conducted in spring 2002 confirms these observations but also reveals a range of borrowings that is far greater than that described by Gilbert (1965) or Guion (1996). For example, a number of Texas German informants used the words tree, food, church, and week instead of their German counterparts der Baum 'tree', das Essen 'food', die Kirche 'church' and die Woche 'week'. The use of these nouns in Texas German cannot be attributed simply to borrowing due to a lack of a similar word in German. Rather, for each of the borrowed nouns, Texas German already has its own German noun to describe the objects or concepts denoted by the loanwords. This observation suggests that Gilbert's (1965: 110) claim that "the actual proportion of English words in German utterances remains small, probably less than 5 percent" needs to be seriously reevaluated once enough data are recorded that reflect the current state of Texas German.

Other areas of the vocabulary that have been influenced by English include prepositional calques (mitaus 'with+out', mitohne 'with+out') (see Guion (1996: 449)) and discourse markers such as well, sure, and right, among others. One of the most interesting current developments in Texas German includes the borrowing of verbs. Whereas previous studies such as Gilbert (1965), Eikel (1967), Salmons (1983), and Guion (1996) report on the borrowing of nouns, discourse markers, and conjunctions (among others), there exists to my knowledge no previous description of verbs being borrowed into Texas German. However, the data recorded in spring 2002 include a number of sentences by different speakers in which English verbs are borrowed into Texas German as the following set of examples illustrates:

(1) a. Ich habe mich behaved. I have myself behaved 'I behaved myself.' b. Ich habe mich benommen.

I have myself behaved

'I behaved myself.'

\footnotetext{
${ }^{10}$ At this preliminary stage it is too early to conduct a detailed analysis of the current state of Texas German (see, e.g., Guion (1996)) because the data have not yet been systematically transcribed, categorized, and analyzed.
} 


\section{Tracing Dialect Death}

In (1a) the English verb behave is borrowed into Texas German, an effective substitution for the Standard German counterpart sich benehmen 'to behave' as seen in (1b). Note that the borrowed verb behave does itself not have a restructuring effect on the syntax of the German sentence in which it occurs, i.e., the structure of the main declarative clause in (1a) remains unaffected by the borrowing of behave. A preliminary analysis of the spring 2002 data reveals a number of other verbs such as beat and come that have apparently made their way into the speech of various Texas German informants. Since the borrowing of verbs into Texas German seems to be a relatively underdescribed phenomenon, it is first necessary to gather more data before making any claims about the range of verb borrowings. ${ }^{11}$

\subsection{Plural Morphology}

The distribution of plural morphemes in Texas German is another feature that has undergone significant changes over the last four decades. For example, Eikel (1967) reports that

[t] he plurals of nouns in NBG are often formed like the plurals of native nouns in Standard German (SG): a. With a plural identical with the singular form, or with vowel modification. $\mathrm{b}$. with the addition of $-e$ to the singular, with or without vowel modification. $c$. With the addition of -er to the singular, with or without vowel modification. $d$. With the addition of $-n$ or $-e n$ to the singular (p.83). ${ }^{12}$

Eikel's (1967) findings are very close to Gilbert's (1963) which also identify the frequency with which individual plural morphemes are used. In particular, Gilbert points out that [-ən] and [-s] are the most frequently occurring plural morphemes, the latter usually being used to pluralize English loan words. While the observations made by Eikel and Gilbert in the 1960s describe a rather rich plural morphology that is relatively close to Standard German, Salmons (1983: 194) points out with respect to paradigm reduction that "we may see the beginning of some breakdown in the language system." Citing the example of Koffer 'suitcase', Salmons observes that the plural form of this noun "is formed with $-\mathrm{n},-\mathrm{s}$, or $-\emptyset$ " (1983: 194).

A preliminary analysis of current fieldwork data confirms Gilbert's 1963 description of [-an] and [-s] as being the plural morphemes employed most frequently. Our preliminary analysis also confirms Salmons' 1983 observation regarding the instability of different plural morphemes occurring with nouns. For example, there are a large number of nouns of German origin whose plurals are

\footnotetext{
1 The current Texas German data strongly suggest that the amount of English words borrowed into the dialect is steadily increasing, an observation already made by Salmons (1983: 193): "[Y]ounger informants used more English loans than older informants." If this trend continues and there is no evidence to the contrary - Gilbert's (1963:110) clain that "the actual proportion of English words in German utterances remains small, probably less than 5 percent" is outdated.

${ }^{12}$ NBG means New Braunfels German.
} 
formed either by suffixation of an [-s] as in (2b) or by employing the zero morpheme as in (2c).
a. das Kind
the child
'the child'
b. die Kinder-s
the child-pl
'the children'
c. die Kinder-ø
the child-pl
'the children'

Although both plural morphemes are used with nouns that occurred exclusively with the zero morpheme some forty years ago, the [-s] variant occurs with a much higher frequency than the zero variant in the 2002 data. This observation suggests that the [-s] plural morpheme is becoming more productive than previously thought.

There also exist a number of nouns that have undergone a different change in how their plural variants are formed. These nouns have previously taken the [-ə] morpheme only to mark their plurality. In contrast, the 2002 data reveal an unsystematic pattern of plural formation as the following examples illustrate.
(3) a. die Freund-en the friend-pl
b. die Freund-s the friend-pl 'the friends' 'the friends'
c. die Freund-ø the friend-pl 'the friends'
d. die Freund-e the friend-pl 'the friends'

The data in (3) show that the plural morpheme attached to the nominative Freund 'friend' currently has four different allomorphs in Texas German as opposed to only one (i.e., [-ə]) some four decades ago. The seemingly unsystematic variation in plural morphology exemplified by ( $3 a-d)$ is not restricted to a small number of nouns but seems to be rather widespread according to a preliminary analysis of the first twenty hours of current recordings.

Unfortunately, there is at this point no large enough corpus of current Texas German data available to conduct in-depth analyses that would reveal the full range of systematic and unsystematic variation in plural morphology. However, if it turns out that similar inconsistent patterns for plural formation prevail across the lexicon then this variation might very well be what Salmons called "the beginning of some breakdown of the language system" (1983: 194).

\subsection{The Case System}

Another area of interest in the study of Texas German is its case system which "has been greatly reduced over its recorded history" (Guion 1996: 454). Whereas the genitive had basically dropped out of Texas German by the 1960s (except for a few fixed phrases) $)^{13}$, the dative has been in recession for some time as well ${ }^{14}$. For example, Eikel (1967: 91) observes that "the use of the dative decreases from

\footnotetext{
${ }^{13}$ See Eikel (1967: 88-89) for a list of examples.

${ }^{14}$ See Eikel (1967: 89-91) for a list of examples.
} 
generation to generation" and that "the accusative is used in many instances for the dative."

A preliminary analysis of the 2002 recordings confirms previous observations regarding the recession of the genitive and dative cases. Of particular interest is the development of the dative case which was used much less frequently than reported by Eikel (1967) ("about half the time expected"). This development has led to the accusative markers taking over most of the functions previously held by genitive and dative markers, thereby leading to the creation to what Gilbert (1965: 109) labels a "new case" or "simply oblique or non-nominative - as opposed to the nominative case." The following examples from the 2002 data illustrate how the accusative in (4a) and (5a) has taken over the functions of the dative in (4b) and $(5 b)$, respectively.

(4)
a. Helf mich!
help me: $A C C$
'Help me!'
(5) a. wegen den Tisch
because the table: $A C C$
'because of the table'

b. Hilf mir!

help me:DAT

'Help me!'

b. wegen des Tisches

because the table: GEN

'because of the table'

Besides the accelerated recession of the dative case, the current recordings reveal another interesting tendency in the development of the Texas German case system. Whereas previous data show that Texas German has reached a stage in its development where the only case opposition is between nominative and accusative (the "new" oblique case), it appears as if even this distinction is beginning to erode. That is, in some instances informants used the nominative instead of the expected accusative as the following examples illustrate.

(6) a. nach der erste Krieg after the first war:NOM 'after the first war' b. nach den ersten Krieg after the first war: $A C C$ 'after the first war'

Example (6b) contains the preposition nach 'after' which is recorded by Eikel (1967: 93) as goveming the "[a]ccusative instead of dative" case. This example by itself is not new since it is an instance of the more general Texas German tendency of dative governing prepositions to govern the accusative case. However, what makes this example interesting is the fact that some of the 2002 informants do not use the accusative case following nach on a regular basis any more. Instead, the nominative case is used to mark noun phrases governed by $n a c h$ as in (6a). So far, none of the informants using the nominative following nach use this case exclusively, but rather in a number of instances while retaining the accusative in other cases. Our preliminary analysis of the data also shows that nominative case marking in oblique case marking positions is not an isolated 
phenomenon. Similar patterns of case erosion are observed with prepositions that have traditionally governed the accusative such as durch 'through'. Example ( $7 \mathrm{~b}$ ) shows how four decades ago, durch used to be a preposition "that regularly require[d] an object in the accusative" (Eikel 1967: 92). In contrast, (7a) exemplifies the use of durch followed by a nominative in the 2002 recordings.
(7) a. durch der erste Krieg through the first war: NOM
b. durch den ersten Krieg through the first war: $A C C$ 'throughout the first war'
'throughout the first war'

Examples such as (6) and (7) suggest that although the functions of the genitive and dative cases have been taken over by accusative markers, even this "new case" (Gilbert 1965: 109) may not be stable as of 2002. At this point of the analysis it is too early to come to definite conclusions about the full range of accusative case erosion. However, the data analyzed so far do suggest that even the accusative case may not be immune to erosion under the influence of other cases, in this case the only remaining case, i.e., the non-oblique nominative.

\subsection{Phonetics/Phonology}

The change in pronunciation of Texas German is one of the most obvious changes that has taken place over the last forty years. In particular, some of the Texas German vowels seem to have undergone a quite dramatic change since their features and distribution were last described in detail by Eikel (1966) and Gilbert (1972), among others.

For example, Eikel (1966) characterizes the vowel in the third person singular of gehen 'to go' as a long mid-high front vowel [e:] as in (8a). In contrast, a preliminary analysis of the 2002 recordings reveals that the majority of informants produce a diphtongized version of this vowel as in (8b) (see Boas, in press). Another change that has taken place in Texas German is in environments in which vowels precede nasals. Eikel reports for siebzehn 'seventeen' a regular long [e:] as in (9a). The 2002 data in (9b) show that this vowel has become both diphtongized and nasalized (see Boas (in press)).
a. [ge:t]
b. [geyt] 'goes'
a. [si:ptse:n]
b. [si:ptsẽyn] 'seventeen'

While both diphtongization and nasalization of long vowels in environments such as (8) and (9) occur quite frequently, it is not entirely clear what the conditioning environments for the nasalization in Vieh 'cattle' and Tag 'day' in the following examples are (see Boas (in press)).
a. [fi:]
b. [fi: ] 'cattle'
a. $[\operatorname{ta}: x]$
b. [tã:x] 'day' 


\section{Tracing Dialect Death}

Besides changes in the vowel system, Texas German has undergone significant changes in its consonant system, in particular in word-initial position. For example, Gilbert (1972) reports that the word-initial consonant in Zimmer 'room' has two variants, i.e., the voiceless affricate [ts] as in (12a) as well as the voiceless alveolar fricative [s] as in (12b). Our preliminary analysis of the 2002 data shows that both variants occur rather infrequently and are instead substituted by the voiced alveolar fricative [z] as in (12c) (see Boas (in press)). Other substitutions observed include cases in which a voiceless palato-alveolar fricative [0] in word-initial position as in (13a) is substituted by a voiceless alveolar fricative [s] in positions in which it is followed by a voiced labio-dental fricative as in (13b) (see Boas, in press).
a. [tsimər]
c. [ziməI] 'room'
b. [simar]

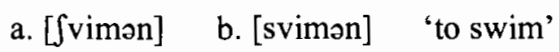

As with the other linguistic changes briefly outlined in this paper, it is at this point of the investigation too early to give a full-fledged description of the current state of Texas German, let alone a full analysis of the underlying factors that have triggered these changes. Our overview of how a number of representative linguistic features of Texas German have drastically changed over the last forty years shows that much work remains to be done. As members of the TGDP are recording more data that are subsequently stored in the TGDA, we hope to build a large enough corpus (at least 100 hours of interviews) that will eventually allow us to produce a detailed inventory of linguistic features of Texas German as it is spoken at the beginning of the new millennium. ${ }^{15}$

\section{Research Questions}

In addition to describing the current state of Texas German, the TGDP will also seek answers to the following research questions in the years to come: (a) Which linguistic features of Texas German have changed over the last four decades and why? (b) Which of these changes can be attributed to contact with English? (c) Are these changes similar to those of other rapidly eroding dialects that are in contact with other languages? (d) Is change in dialect death different from other types of language change? (e) How close is Texas German to becoming extinct? (f) What are the sociolinguistic causes leading to language shift from German to English? (g) What types of German words are retained by members of the Texas

\footnotetext{
is To this end, members of the TGDP will not only have to conduct more interviews with informants who live in the areas that comprise the three current fieldwork sites (Fredericksburg, New Braunfels, Freyburg, and Round Rock). It is also planned to add further fieldwork sites across Washington, Austin, Fayette, DeWitt, and Medina counties to the research area of the TGDP.
} 
German speech community who have shifted to English? (h) In which situations do bilinguals code-switch from Texas German to English and vice versa?

\section{References}

Barbour, S. and P. Stevenson. 1990. Variation in German. Cambridge: CUP. Boas, H.C. in press. The Texas German Dialect Archive as a tool for analyzing sound change. Proceedings of the Workshop on Methods and Tools in Field Linguistics. Held in conjunction with the Third International Conference on Language Resources and Evaluation. Las Palmas, Spain.

Biesele, R.L. 1928. A History of the German Settlements in Texas. Ph.D. dissertation, UT Austin.

Crystal, D. 2000. Language Death. Cambridge: CUP.

Dorian, N.C. 1982. Linguistic models and language death evidence. In L.K.

Obler and L. Menn (eds.) Exceptional Languages and Linguistics, 31-48. New York: Academic Press.

Eikel, F. 1949. The use of cases in New Braunfels German. American Speech, 24: $278-281$.

Eikel, F. 1954. The New Braunfels German Dialect. Baltimore:

Eikel, F. 1966. New Braunfels German: Part II. American Speech 41: 254-160.

Eikel, F. 1967. New Braunfels German: Part III. American Speech 42: 83-104.

Gilbert, G. 1963. The German Dialect spoken in Kendall and Gillespie Counties, Texas. Ph.D. dissertation, Harvard University.

Gilbert, G. 1965. English loanwords in the German of Fredericksburg, Texas. American Speech 40: 102-112.

Gilbert, G. 1972. Linguistic Atlas of Texas German. Austin: UT Press.

Guion, S. 1996. The death of Texas German in Gillespie County. In P.S. Ureland and I. Clarkson (eds.) Language contact across the North Atlantic, 443-463. Tübingen: Niemeyer.

Salmons, J.C. 1983. Issues in Texas German language maintenance and shift. Monatshefte 75:187-196.

Hans C. Boas

Department of Germanic Studies

E.P.S. $3.102, \mathrm{C} 3300$

University of Texas at Austin

Austin, TX 7812-1190, U.S.A.

hcb@mail.utexas.edu 